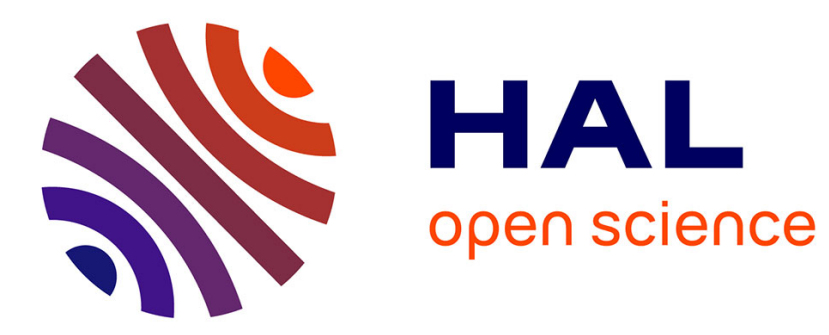

\title{
Systematic equity-based credit risk: A CEV model with jump to default
}

Luciano Campi, Simon Polbennikov, Alessandro Sbuelz

\section{To cite this version:}

Luciano Campi, Simon Polbennikov, Alessandro Sbuelz. Systematic equity-based credit risk: A CEV model with jump to default. Journal of Economic Dynamics and Control, 2009, 33 (1), pp.93-108. hal-00361385

\section{HAL Id: hal-00361385 \\ https://hal.science/hal-00361385}

Submitted on 13 Feb 2009

HAL is a multi-disciplinary open access archive for the deposit and dissemination of scientific research documents, whether they are published or not. The documents may come from teaching and research institutions in France or abroad, or from public or private research centers.
L'archive ouverte pluridisciplinaire HAL, est destinée au dépôt et à la diffusion de documents scientifiques de niveau recherche, publiés ou non, émanant des établissements d'enseignement et de recherche français ou étrangers, des laboratoires publics ou privés. 


\title{
Systematic Equity-Based Credit Risk: A CEV Model with Jump to Default
}

\author{
Luciano Campi* Simon Polbennikov†, and Alessandro Sbuelz $z^{\ddagger}$
}

August 2007

\footnotetext{
${ }^{*}$ CEREMADE, Université Paris Dauphine, Place du Maréchal de Lattre de Tassigny, 75775, Paris Cedex 16, Phone: +33 (0) 14405 4882, Fax: +33 (0)1 44-05-45-99, E-mail: campi@ceremade.dauphine.fr.

${ }^{\dagger}$ Econometrics and Operations Research, Tilburg University, The Netherlands, Phone: +31-13-4663426, E-mail: s.y.polbennikov@uvt.nl.

${ }^{\ddagger}$ Corresponding author. Department of Economics, SAFE Center, University of Verona, Via Giardino Giusti 2, 37129, Verona, Italy, Phone: +39-045-8054922 , Fax: +39-045-8054935 , E-mail: alessandro.sbuelz@univr.it.
} 


\title{
Systematic Equity-Based Credit Risk: A CEV Model with Jump to Default
}

\begin{abstract}
We use equity as the traded primitive for a detailed analysis of systematic default risk. Default is parsimoniously represented by equity value hitting the zero barrier so that, unlike in reduced-form models, the explicit linkage to the firm's capital structure is preserved, but, unlike in structural models, restrictive assumptions on the structure are avoided. Default risk is either jump-like or diffusive. The equity price can jump to default: In line with recent empirical evidence on the jump-to-default risk price, we highlight how reasonable choices of the pricing kernel can imply remarkable differences in the equity-price-dependent status between the objective default intensity and the risk-neutral intensity. As equity returns experience negative diffusive shocks, their CEV-type local variance increases and boosts the objective and risk-neutral probabilities of diffusive default. A parsimonious version of our general model simultaneously enables analytical credit-risk management and analytical pricing of credit-sensitive instruments. Easy cross-asset hedging ensues.
\end{abstract}

JEL-Classification: G12, G33.

Keywords: Market Price of Credit Risk, Constant-Elasticity-of-Variance (CEV) Diffusive Risk, Jump-to-Default Risk, Equity, Corporate Bonds, Credit Default Swaps. 


\section{Introduction}

For individual firms in segments of the market with high default risk, default risk and equity returns exhibit a clear link and default risk appears to be systematic (see Vassalou and Xing (2004)). Observed market prices of risk include the jump-to-default risk price, which tends to balloon at times of bear equity markets (see Berndt, Douglas, Duffie, Ferguson, and Schranz (2005) and Berndt, Lookman, and Obreja (2006)). The credit-equity link has been attracting attention from credit risk managers. In their effort of assessing actual distances from default, they have been courting credit-risk models that focus on equity data ${ }^{1}$ and that, given the systematic nature of default risk, explicitly treat the relationship between the objective probability measure and the pricing measure(s). An equity-based model that directly studies the change of measure (implied by the pricing kernel) enables a better informed assessment of the objective probability of default by supporting a consistent integration of equity market data, of equity options market data, and of market data on other credit-sensitive instruments. Since cross-asset trading of credit risk has been gaining momentum ${ }^{2}$ among hedge funds and banks, model by-products like analytical results under the pricing measure(s) will also benefit investors.

Reduced-form models (see Jarrow and Turnbull (1995) among the seminal papers and the reviews in Lando (2004) and Schönbucher (2003)) are of limited help, as they do not consider the direct linkage to the firm's capital structure. Structural models are driven by the value evolution in firm's assets. The assets-value evolution is often assumed to be diffusive so that the default can be seen predictably coming by observing changes in the capital structure of the firm (see the seminal papers of Merton (1974) and Black and Cox (1976), and the reviews in Lando (2004) and Schönbucher (2003)). While appealing, structural models suffer when it comes to applications ${ }^{3}$.

\footnotetext{
${ }^{1}$ Fore example, KMV output for public firms is strongly driven by equity-value data.

${ }^{2}$ The rise of capital structure arbitrage is a good example (see Schaefer and Strebulaev (2006)).

${ }^{3}$ For an empirical analysis of structural models based on corporate-bond price data,
} 
The underlying (the sum of firm's liabilities and equity) is illiquid and often non-tradable. Obtaining accurate asset volatility forecasts and dependable capital structure leverage data is difficult. Predictability of the default event implies the counterfactual prediction of zero credit spreads for short maturities $^{4}$ and, last but not least, arbitrary use of the structural default barrier is often a temptation hard to resist-endogenous barriers ${ }^{5}$ come with a practicability issue because the capital-structure assumptions under which they are derived are not fully realistic.

We propose a credit risk model that does look at the firm's balance sheet but avoids the application mishaps of structural models. We take as underlying the most liquid and observable corporate security: Equity ${ }^{6}$. This modelling choice brings in hedging viability and the possibility of minimizing the dependability issue in model calibration-leverage information from book values can be circumvented. We represent default as equity value hitting the zero barrier either with a jump or diffusively. The presence of an equity-value drop to zero has its credit-risk foundation in the incompleteness of accounting information (see Duffie and Lando (2001)), rules out default predictability, and embeds the concept of unexpected default, typical of reduced-form models, within a credit-risk model that is directly based on equity. We assume that the continuous-path part of equity value is a Constant-Elasticity-of-Variance (CEV) diffusion ${ }^{7}$, which enables a possee for example Eom, Helwege, and Huang (2004).

${ }^{4}$ Zhou (1997) posits assets-value jumps to overcome default predictability. Duffie and Singleton (2001) explain such jumps with the presence of incomplete accounting information.

${ }^{5}$ See for example Leland and Toft (1996), Acharya and Carpenter (2002), and references therein.

${ }^{6}$ It must be remarked that, while equity shares are indeed the most liquid and observable securities, equity-based products are not always so. For example, implied volatilities for equity options with strikes such as those involved in equity default swaps are not available directly, and often need be mutuated by credit products such as credit default swaps (CDS). There are instances where CDSs provide more liquid information than equity. In general, CDSs are now fundamental liquid credit products.

${ }^{7}$ The CEV process has been first introduced to finance by Cox (1975). Among others, 
itive probability ${ }^{8}$ of diffusive absorption at zero. Unlike in structural models, credit risk can be directly related to the so-called 'leverage effect' (the negative link between equity returns' volatility and equity price observed in equity markets as well as in equity options markets) under the CEV assumption, because the primitives are equity returns and their volatility skews rather than the unobserved market value of assets ${ }^{9}$.

Under these assumptions, we study incomplete-markets equity-based credit risk under the objective probability measure as well as under the pricing measure(s), so that risk premia receive explicit and careful treatment. Our study brings an interesting economic and technical contribution, as the existing literature on equity-based jump-to-default credit risk focuses on pricing-measure analysis ${ }^{10}$ and avoids the economic and technical treatment of default risk premia. Technically, we prove that the state price densities we consider do back equivalent martingale measures, also in uncharted regions of the parameters where the 'leverage effect' is particularly strong. Economically, we show that reasonable choices of the pricing kernel can be consistent with mounting empirical evidence that the two components of the jump-to-default risk price exhibit remarkable differences in their equity-price-dependent status. The jump-to-default risk price is captured by the ratio $\frac{\lambda_{\mathbb{Q}}}{\lambda_{\mathbb{P}}}$ between the risk-neutral default intensity $\lambda_{\mathbb{Q}}$ and

the CEV-based asset-pricing literature includes the works of Albanese, Campolieti, Carr, and Lipton (2001), Beckers (1980), Boyle and Tian (1999), Cox and Ross (1976), Davydov and Linetsky (2001), Emanuel and MacBeth (1982), Forde (2005), Goldenberg (1991), Leung and Kwok (2005), Lo, Hui, Yuen (2000), Lo, Hui, and Yuen (2001), Lo, Tang, Ku, and Hui (2004), Sbuelz (2004), and Schroder (1989).

${ }^{8}$ Merton (1976) considers equity price's possible jump to zero, but no diffusive absorption at zero with positive probability.

${ }^{9}$ Hull, Nelken, and White (2004) study the link between credit risk and equity volatility skews in Merton's (1974) model, within which an option on the firm's equity is a compound option on the firm's assets.

${ }^{10}$ See the pricing analysis in Linetsky (2006), who has introduced some of the pricing motivations for pursuing research on equity-based credit risk, and the pricing analysis in Carr and Linetsky (2006), who have studied the pricing implications of a Jump-to-Default Extended CEV (JDCEV) model. 
the objective intensity $\lambda_{\mathbb{P}}$. The variance-optimal kernel, which is known to suit market players with hedging needs (for example, see Bertsimas, Kogan, and Lo (2001), Biagini and Cretarola (2005, 2006), Bielecki, Jeanblanc and Rutkowski (2004a, b, c, d), Henderson and Hobson (2003), and Schweizer (2001)), can easily agree with the fact that observed increases in $\lambda_{\mathbb{Q}}$ come from increases in the jump-to-default risk price due to sliding equity valuations rather than from fluctuations in $\lambda_{\mathbb{P}}$. While $\lambda_{\mathbb{P}}$ looks pretty stable through time, significant equity-driven variation is observed in the jump-todefault risk price, with recent peaks corresponding to the late-2002 wretched equity markets (see Berndt, Douglas, Duffie, Ferguson, and Schranz (2005) and Berndt, Lookman, and Obreja (2006)). A possible conjecture is that, among other things, keenness to be hedged against default risk might be boosted by bear equity markets, even if they are accompanied by only a slight increase in the objective likelihood of default.

In the second part of this work, we discuss a parsimonious version of our general model. It uses the same technical steps to simultaneously enable analytical credit-risk management and analytical pricing of credit-sensitive instruments. A frugal specification of the state-price density is conducive to a closed form for the objective default probabilities. Under the pricing measure, formulae for Corporate Bond (CB) prices and Credit Default Swap (CDS) fees are obtained, from which hedge ratios can be easily calculated. Empirical tests show that parsimony empowers the model with analytical results without jeopardizing its flexibility.

Albanese and Chen (2004) and Campi and Sbuelz (2006) also use a CEVequity model to price credit instruments but they ignore the default predictability issue and the analysis of default-risk premia. In deriving closedform values, we build upon a CEV result in Campi and Sbuelz (2006). Naik, Trinh, Balakrishnan, and Sen (2003) and Trinh (2004) introduce a hybrid debt-equity model that considers equity as primitive but that, like structural models, necessitates a free default barrier, which is then left to potentially ad-hoc uses-equity value is assumed to be a geometric Brownian motion. Das and Sundaram (2003) have proposed an equity-based model that ac- 
counts for default risk, interest risk, and equity risk using a lattice framework. As such, they do not seek hedger-friendly analytical solutions and do not deal explicitly with default-risk premia. Those aspects are also missing in the numerical equity-based credit-risk pricing that has been suggested by the convertible bond ${ }^{11}$ literature (see, for example, Andersen and Andreasen (2000), Andersen and Buffum (2003), and Tsiveriotis and Fernandes (1998); McConnell and Schwartz (1986) ignore the possibility of bankruptcy). In Cathcart and El-Jahel (2003), default occurs when a geometric-Brownianmotion signaling variable, interpreted as the credit quality of the reference entity, hits a lower default barrier or according to a hazard rate process, so that both expected and unexpected defaults are accomodated in a single framework. However, the signaling variable can hardly be identified with equity value (the default barrier is above the inaccessible zero level and there is no 'leverage effect') and the concern of a possibly freewheeling default barrier remains. Such a concern is unlikely to have no impact on the calculation of impied default barriers from market quotes. Hui, Lo, and Tsang (2003) use a dynamic default barrier to achieve an empowered calibration of CB spreads. Brigo and Tarenghi (2005a, 2005b) and Brigo and Morini (2006) employ a flexible time-varying default barrier (the barrier is random in Brigo and Morini (2006)) to accurately calibrate CDS market data.

Linetsky (2006) builds upon the convertible bond literature to assess zero-coupon $\mathrm{CB}$ prices ${ }^{12}$ within a geometric-Brownian-motion model with jump-like bankruptcy where the hazard rate of bankruptcy is a negative power of the share price. Carr and Linetsky (2006) consider a general setup of a jump-to-default extended diffusion with arbitrary local volatility and intensity functions. In particular, they take the stock price to follow a CEV diffusion, punctuated by a possible jump to zero (the JDCEV model). To

\footnotetext{
${ }^{11}$ See Nelken (2000) for a review of hybrid debt-equity instruments.

${ }^{12}$ Linetsky (2006) considers recovery payments at maturity. Guha and Sbuelz (2005) argue that a more realistic recovery assumption for corporate bonds is the partial recovery of the face value at the default date regardless of maturity. See later Propositions (5) and (6) and their discussion.
} 
capture the possible positive link between default and volatility, they assume that the hazard rate of default is an increasing affine function of the instantaneous variance of returns on the underlying stock. Linetsky (2006) and Carr and Linetsky (2006) pursue a risk-neutral pricing analysis overlooking the study of the existence of some equivalent martingale measure in their incomplete-markets setting-with CEV-like complete markets, Delbaen and Shirakawa (2002) derive existence results for a given lower bound on the CEV parameter. Since default-risk premia are not treated, no discussion of the objective probability of default and of the pricing-kernel-based choice of an equivalent martingale measure is attempted. By contrast, the systematic nature of CEV-like diffusive risk as well as of jump-to-default risk are at the core of our work. In particular, while proving that the pricing kernels ${ }^{13}$ we study do support equivalent martingale measures, we extend the existence result of Delbaen and Shirakawa (2002) to any negative value of the CEV parameter. Such a parameter region is particularly relevant for credit risk: The more negative the CEV parameter, the higher the probability of diffusive default and the more negative the link between equity returns' volatility and equity price.

The rest of the work is organized as follows. Section 2 describes the general model for the equity market, the market price of credit risk, and its related pricing kernel. Section 3 considers a parsimonious version of the general model that simultaneously enables analytical credit-risk management and analytical pricing of credit-sensitive instruments. Section 4 concludes. An Appendix gathers lengthy proofs, analytical formulae, and

\footnotetext{
${ }^{13}$ Since the jump to default is not a stopping time of the filtration generated by the continuous-path part of the stock price, our chosen Radon-Nikodym derivative is similar to the one coming from dynamic asset pricing theory with uncertain time-horizon, Blanchet-Scaillet, El Karoui, and Martellini (2005), Proposition 2. Bellamy and Jeanbleanc (2000) analyze the incompleteness of markets driven by a mixed diffusion, construct a similar Radon-Nikodym derivative, and, among other contingent claims, study American contracts. Both Blanchet-Scaillet, El Karoui, and Martellini (2005) and Bellamy and Jeanbleanc (2000) assume bounded local volatility for the stock returns, which is not our CEV case. They also refrain from considering default-driven time-horizon uncertainty.
} 
details about model extensions with time-dependent coefficients and about model-based hedging.

\section{Credit risk under the objective probability mea- sure}

A sound assessment of a counterpart's credit risk under the objective default probability is crucial for any credit risk management system. Financial institutions and banks in particular seek it to assist decisions on approving loans, portfolio monitoring and management reporting, capital allocation, risk-adjusted performance measurement and loan pricing. Regulatory pressure has been adding motivation. The New Basel Capital Accord allows the use of internal ratings systems to determine the appropriate level of reserves to support corporate-exposure activities and other credit risky activities.

We consider an arbitrage-free incomplete market where, under the objective probability measure $\mathbb{P}$, the reference entity's share price process $\{S\}$ has the following pre-default jump-diffusion dynamics:

$$
\frac{\mathrm{d} S_{t}}{S_{t-}}=\mu_{\mathbb{P}}\left(S_{t-}\right) \mathrm{d} t+\sigma S_{t-}^{\rho-1} \mathrm{~d} z_{t}^{\mathbb{P}}-\left(\mathrm{d} N_{t}^{\mathbb{P}}-\lambda_{\mathbb{P}}\left(S_{t-}\right) \mathrm{d} t\right)
$$

where $\left\{z^{\mathbb{P}}\right\}$ is a Wiener process and $\left\{N^{\mathbb{P}}\right\}$ is a first-jump-stopped marked point process:

$$
\begin{aligned}
N_{t}^{\mathbb{P}} & =1_{\{t \geq \tau\}}, \\
\tau & \equiv \inf \left\{t: N_{t}^{\mathbb{P}}=1\right\} \quad \text { (time of the only jump). }
\end{aligned}
$$

The underlying filtration $\left(\mathcal{F}_{t}\right)$ is generated by $\left\{z^{\mathbb{P}}\right\},\left\{N^{\mathbb{P}}\right\}$, and $\left\{\zeta \mathbf{1}_{\{\tau<t\}}\right\}$ and satisfies the usual conditions of right-continuity and $\mathbb{P}$-completeness. $\operatorname{Under}\left(\mathcal{F}_{t}\right)$, the jump-risk-pricing random variable $\zeta$ (we assume $E^{\mathbb{P}}[\exp (\zeta)]$ 
bounded) and the processes $\left\{z^{\mathbb{P}}\right\}$ and $\left\{N^{\mathbb{P}}\right\}$ are mutually independent. While the form ' $\sigma S_{t-}^{\rho-1}$, of the local diffusive volatility suits the CEV-diffusion focus of the present work, a general form of the local diffusive volatility is fully consistent with the no-arbitrage analysis developed in this section, as long as it is accompanied by a bounded price of diffusive risk and it differs from zero (see later our assumptions on the adapted process $\{\theta\}$ and see Lemma (8) in the Appendix). By remaining unchanged under the pricing measure of choice, such a general form of the local diffusive volatility agrees with the pricing-measure analysis developed in the sections 2 and 3 of Carr and Linetsky (2006), pp. 306-311. The time of absorption at zero in the absence of jumps is $\xi$, that is

$$
\xi \equiv \inf \left\{t: S_{t}=0, N_{t}=0\right\},
$$

whereas the time of absorption at zero tout court is the minimum between $\tau$ and $\xi$, that is

$$
\tau \wedge \xi=\inf \left\{t: S_{t}=0\right\} .
$$

The point 0 is the absorbing state of the share-price process $\{S\}$, so that, once default has occurred, the share price remains at zero,

$$
S_{t}=0, \quad \forall t \geq \tau \wedge \xi
$$

The other main objects directly or indirectly appearing in Equation (1) are:

$$
\begin{aligned}
S & \equiv S_{0} & & \text { (current share price) } \\
S_{t-} & \equiv \lim _{\varepsilon}{ }_{0} S_{t-\varepsilon} & & \text { (left time limit of the share price), } \\
\rho-1 & <0 & & \text { (constant elasticity of the diffusive volatility) }, \\
T & >0 & & \text { (finite maturity, in years), } \\
\lambda_{\mathbb{P}}\left(S_{t-}\right) & \geq 0 & & \text { (jump-to-default intensity), }
\end{aligned}
$$

where the $\mathbb{P}$-intensity $\lambda_{\mathbb{P}}\left(S_{t-}\right)$ is a non-negative bounded function of the pre-default share price $S_{t-}$. The objective chance of seeing no jump is

$$
E_{t}^{\mathbb{P}}\left[1_{\{\tau>T\}}\right]=E_{t}^{\mathbb{P}}\left[\exp \left(-\int_{t}^{T} \lambda_{\mathbb{P}}\left(S_{u-}\right) \mathrm{d} u\right)\right] .
$$


We also introduce the time of absorption at zero of the continuous part $\left\{S^{c}\right\}$ of $\{S\}$, that is,

$$
\xi^{c} \equiv \inf \left\{t: S_{t}^{c}=0\right\}
$$

where

$$
\frac{\mathrm{d} S_{t}^{c}}{S_{t}^{c}}=\mu_{\mathbb{P}}\left(S_{t-}\right) \mathrm{d} t+\sigma\left(S_{t}^{c}\right)^{\rho-1} \mathrm{~d} z_{t}^{\mathbb{P}}+\lambda_{\mathbb{P}}\left(S_{t-}\right) \mathrm{d} t
$$

\subsection{Expected equity returns and the market price of credit risk}

We take the bounded function $\theta\left(S_{t-}\right)$ as a vehicle of diffusive risk pricing, and the random variable $\zeta$ and the positive bounded function $F\left(S_{t-}\right)$ as vehicles of jump-to-default risk pricing. The share's instantaneous expected capital gain conditional upon $S_{t-}, \mu_{\mathbb{P}}\left(S_{t-}\right)$, takes the following percentage form:

$$
\begin{aligned}
\mu_{\mathbb{P}}\left(S_{t-}\right)=r-q+\theta\left(S_{t-}\right) \sigma+\left(E^{\mathbb{P}}[\exp (\zeta)] F\left(S_{t-}\right)-1\right) \lambda_{\mathbb{P}}\left(S_{t-}\right) & \\
r-q & =\text { share's cost of carry, } \\
\theta\left(S_{t-}\right) \sigma & =\text { premium for the diffusive risk, } \\
\left(E^{\mathbb{P}}[\exp (\zeta)] F\left(S_{t-}\right)-1\right) \lambda_{\mathbb{P}}\left(S_{t-}\right) & =\text { premium for the jump-like default risk, }
\end{aligned}
$$

where $r$ is the constant riskfree rate, $q$ is the constant dividend yield, $\sigma$ $(\sigma>0)$ is a constant scale factor for the diffusive volatility.

Proposition (1) states that, in our arbitrage-free incomplete market, the above specification for $\mu_{\mathbb{P}}\left(S_{t-}\right)$ is equivalent to fix the description of the chosen state-price-density process $\{\pi\}$. 
Proposition 1 For $t<\tau \wedge \xi$, the $\mathbb{P}$-dynamics of the state-price-density process $\{\pi\}$ is

$$
\begin{aligned}
\frac{\mathrm{d} \pi_{t}}{\pi_{t-}}= & -r \mathrm{~d} t \\
& -\theta\left(S_{t-}\right) S_{t-}^{1-\rho} \cdot \mathrm{d} z_{t}^{\mathbb{P}} \\
& +\left(\left(\exp (\zeta) F\left(S_{t-}\right)-1\right) \cdot \mathrm{d} N_{t}^{\mathbb{P}}-\left(E^{\mathbb{P}}[\exp (\zeta)] F\left(S_{t-}\right)-1\right) \lambda_{\mathbb{P}}\left(S_{t-}\right) \mathrm{d} t\right),
\end{aligned}
$$

and, for $t \geq \tau \wedge \xi$,

$$
\pi_{t}=\pi_{\tau \wedge \xi} \exp (-r(t-\tau \wedge \xi))
$$

Proof. If the process $\{\pi\}$ has the stated $\mathbb{P}$-dynamics (notice that $\{\pi\}$ 's expected $\mathbb{P}$-growth rate is the usual $-r$ as the cumulative premium for the jump-like default risk,

$$
E^{\mathbb{P}}[\exp (\zeta)] \int_{0}^{t}\left(F\left(S_{u-}\right)-1\right) \lambda_{\mathbb{P}}\left(S_{u-}\right) \mathrm{d} u,
$$

compensates $\{\pi\}$ 's jump process component), then there are no arbitrage opportunities. Indeed, by virtue of Itô's Formula, the $\pi$-deflated gain processes generated by holding one share and by holding one unit of currency in the money-market account are local $\mathbb{P}$-martingales,

$$
E_{t}^{\mathbb{P}}\left[\mathrm{d}\left(\pi_{t} \cdot S_{t} \exp (q t)\right)\right]=0, \quad E_{t}^{\mathbb{P}}\left[\mathrm{d}\left(\pi_{t} \cdot \exp (r t)\right)\right]=0,
$$

and, hence, the market is arbitrage-free ${ }^{14}$.

As for diffusive risk, the usually-assumed negative relationship between the state-price density and the underlying stock price implies positiveness of the pricing function $\theta\left(S_{t-}\right)$. If the premium for diffusive risk vanishes, it is either because such a risk is not priced $(\sup \theta \downarrow 0)$ or because the risk is dimming $(\sigma \downarrow 0)$. As for jump risk, the state price density exhibits a sudden move from $\pi_{\tau-}$ to $\pi_{\tau}$ in the case of a jump to default $(\tau \wedge \xi=\tau)$,

$$
\pi_{\tau}=\pi_{\tau-} \exp (\zeta) F\left(S_{t-}\right) .
$$

\footnotetext{
${ }^{14}$ This rules out arbitrage opportunities involving $S_{t} \exp (q t)$ and $\exp (r t)$, under natural conditions on dynamic trading strategies. See, for example, Appendix B.2 in Pan (2000).
} 
Since $\pi_{\tau}$ represents the fair present value of 1 unit of currency received at the time of jump-like default per unit probability of such an event, only a structural absence of discontinuity between $\pi_{\tau-}$ and $\pi_{\tau}$ will imply that jumpto-default risk is not systematic $\left(\exp (\zeta) F\left(S_{t-}\right)=1 \mathbb{P}\right.$-a.s. $)$. The element $\exp (\zeta)$ brings additional flexibility to the sudden move of the state-price density at the jump-to-default date, on top of the component $F\left(S_{t-}\right)$ that relates such a move to the market conditions prevailing just before default. The degree of freedom contributed by $\exp (\zeta)$ to the $\{\pi\}$-related specification of market participants' preferences can be valuable in applications.

Given the assumed boundedness of $\theta\left(S_{t-}\right)$ and $E^{\mathbb{P}}[\exp (\zeta)] F\left(S_{t-}\right)$, the chosen state-price density process does support an equivalent martingale measure $\mathbb{Q}$. Proposition (2) states that the $\pi$-deflated gain process generated by holding one unit of currency in the money-market account is also a $\mathbb{P}$ martingale. Its $T$-time level represents the Radon-Nikodym derivative of $\mathbb{Q}$ with respect to $\mathbb{P}, \pi_{T} \exp (r T)=\frac{\mathrm{d} \mathbb{Q}}{\mathrm{d} \mathbb{P}}$.

Proposition 2 Let $\pi_{t}$ be defined as above and let $T>0$ be any finite time horizon. Then, the local $\mathbb{P}$-martingale process $\left\{e^{r t} \pi_{t}\right\}$, is a $\mathbb{P}$-martingale over $[0, T]$.

Proof. See the Appendix.

By classic jump-diffusion Cameron-Martin-Girsanov results (see Jacod and Shiryaev (1988)) the risk-neutral jump-to-default intensity $\lambda_{\mathbb{Q}}\left(S_{t-}\right)$ is proportional to the objective intensity $\lambda_{\mathbb{P}}\left(S_{t-}\right)$ via the pricing kernel's relative jump at the time of unpredictable default:

$$
\frac{\lambda_{\mathbb{Q}}\left(S_{t-}\right)}{\lambda_{\mathbb{P}}\left(S_{t-}\right)}=E^{\mathbb{P}}[\exp (\zeta)] F\left(S_{t-}\right) .
$$

Our general shape for the intensities ratio can account for the most recent empirical findings on the jump-to-default risk price $\frac{\lambda_{\mathbb{Q}}}{\lambda_{\mathbb{P}}}$. Jump-to-default risk is priced ( $\frac{\lambda_{\mathbb{Q}}}{\lambda_{\mathbb{P}}}$ tends to differ from 1; cfr. Driessen's (2005) reduced-form study of corporate debt returns) and its price varies over time with market conditions $\left(\frac{\lambda_{\mathbb{Q}}}{\lambda_{\mathbb{P}}}\right.$ varies with $S_{t-}$; cfr. Berndt, Douglas, Duffie, Ferguson, 
and Schranz' (2005) and Saita's (2006) reduced-form studies of default swap rates and estimated default frequencies and of corporate debt returns, respectively). Interestingly, Berndt, Douglas, Duffie, Ferguson, and Schranz (2005) find that, while $\lambda_{\mathbb{P}}$ tends to have moderate fluctuations over time, $\lambda_{\mathbb{Q}}$ is much more time-varying with peaks at times of markets' reduced riskbearing capacity (see the situation in the third quarter of 2002). These peaks drive jump-to-defaut risk compensation to relatively high levels. Berndt, Lookman, and Obreja (2006) extend Vassalou and Xing' (2004) empirical analysis to find that the interaction between the pricing kernel and equity returns is due mainly to the quantity $\frac{\lambda_{\mathbb{Q}}}{\lambda_{\mathbb{P}}}$, which they also find to exhibit considerable fluctuation through time.

\subsection{The variance-optimal pricing kernel}

In an incomplete market, it is natural to look for a best approximation of a non-attainable claim by the value of a self-financing trading strategy toghether with an initial injection of capital. A quadratic criterion can be used to measure the quality of this approximation, in the sense that the best proxy is taken to be the projection ${ }^{15}$ of the claim on the value space generated by self-financing strategies. The initial capital associated to the best-proxy strategy can be calculated as the $\mathbb{P}$-expectation of the claim deflated by the variance-optimal pricing kernel process ${ }^{16}\left\{\pi^{*}\right\}$. Hence, the variance-optimal kernel not only provides the unique no-arbitrage price of attainable claims but also yields the value of non-attainable claims with respect to the reasonable criterion of best quadratic replication. Proposition

\footnotetext{
${ }^{15}$ Square integrability is assumed for the claim as well as for the trading strategies' value. The claim's terminal date can be the minimum between a fixed maturity and a credit-sensitive stopping time. Defaultable-claims hedging has been recently studied by, among others, Biagini and Cretarola (2005, 2006), Bielecki, Jeanblanc and Rutkowski (2004a, b, c, d).

${ }^{16}$ Since the pricing kernel $\left\{\pi^{*}\right\}$ supports the Radon-Nikodym derivative of the varianceoptimal martingale measure $\mathbb{Q}^{*}$ w.r.t. the objective measure $\mathbb{P}$, labelling $\pi^{*}$ "varianceoptimal kernel' is a slight abuse of notation that finds justification in keeping the credit-risk management analysis under its natural context, that is, under $\mathbb{P}$.
} 
(3) explicitly carachterizes $\left\{\pi^{*}\right\}$ 's structure in the context of our market.

Proposition 3 Assume the following majorant restriction on the conditional expected excess return on equity:

$$
0 \leq \mu_{\mathbb{P}}\left(S_{t-}\right)-(r-q)<\sigma^{2} S_{t-}^{2(\rho-1)}+\lambda_{\mathbb{P}}\left(S_{t-}\right) .
$$

The variance-optimal state-price-density process $\left\{\pi^{*}\right\}$ is such that

$$
\begin{aligned}
\theta^{*}\left(S_{t-}\right) S_{t-}^{1-\rho} & =\frac{\mu_{\mathbb{P}}\left(S_{t-}\right)-(r-q)}{\sigma^{2} S_{t-}^{2(\rho-1)}+\lambda_{\mathbb{P}}\left(S_{t-}\right)} \sigma S_{t-}^{\rho-1}, \\
\exp \left(\zeta^{*}\right) F^{*}\left(S_{t-}\right) & =1+\frac{\mu_{\mathbb{P}}\left(S_{t-}\right)-(r-q)}{\sigma^{2} S_{t-}^{2(\rho-1)}+\lambda_{\mathbb{P}}\left(S_{t-}\right)}, \\
\zeta^{*} & =0 \quad \mathbb{P} \text {-almost surely. }
\end{aligned}
$$

Proof. In our jump-diffusion setting, the variance-optimal martingale measure coincides with the minimal martingale measure (the Remark 4.1 in Henderson and Hobson (2003) applies and the majorant restriction on $\mu_{\mathbb{P}}\left(S_{t-}\right)$ avoids situations in which the minimal martingale measure is signed), so that $\left\{\pi^{*}\right\}$ is also the minimal pricing kernel. The minimal pricing kernel is such that $\mathbb{P}$-martingales that are orthogonal to the martingale part of the equity price process $\{S\}$ remain $\mathbb{P}$-martingales even after being deflated by the minimal kernel itself (cfr. Schweizer (2001) among others). Hence, $\left\{\pi^{*}\right\}$ must have the following $\mathbb{P}$-dynamics:

$$
\frac{\mathrm{d} \pi_{t}^{*}}{\pi_{t-}^{*}}=-r \mathrm{~d} t+\eta_{t}^{*}\left(\frac{\mathrm{d} S_{t}}{S_{t-}}-\mu_{\mathbb{P}}\left(S_{t-}\right) \mathrm{d} t\right)
$$

where $\frac{\mathrm{d} S_{t}}{S_{t-}}-\mu_{\mathbb{P}}\left(S_{t-}\right) \mathrm{d} t$ is the martingale increment of $\{S\}$. The kernel $\left\{\pi^{*}\right\}$ must also correctly price traded securities like equity, that is,

$$
E_{t}^{\mathbb{P}}\left[\mathrm{d}\left(\pi_{t}^{*} \cdot S_{t} \exp (q t)\right)\right]=0,
$$


or, equivalently by virtue of Itô's Formula,

$$
\mu_{\mathbb{P}}\left(S_{t-}\right)+q-r+\eta_{t}^{*} \cdot \sigma^{2} S_{t-}^{2(\rho-1)}+\eta_{t}^{*} \cdot \lambda_{\mathbb{P}}\left(S_{t-}\right)=0 .
$$

The remark that

$$
\theta^{*}\left(S_{t-}\right) S_{t-}^{1-\rho}=-\eta_{t}^{*} \sigma S_{t-}^{\rho-1} \quad \text { and } \quad \exp \left(\zeta^{*}\right) F^{*}\left(S_{t-}\right)-1=-\eta_{t}^{*},
$$

completes the proof.

The proof emphasizes that $\left\{\pi^{*}\right\}$ 's choice is sensible from the point of view of market players with hedging needs. Since $\left\{\pi^{*}\right\}$ is also the minimal kernel, the $\mathbb{P}$-expectation of a (possibly non-attainable) claim deflated by $\left\{\pi^{*}\right\}$ is not only the initial capital necessary to reproduce the claim's projection on the value space of self-financing strategies, but also represents the initial cost of the trading strategy that yields an exact replica of the claim and that, although it may require intermediate injections/withdrawals of cash, is self-financing 'on average' and minimizes the conditional size of possible intermediate injections/withdrawals (cfr. Schweizer (2001) among others).

Most importantly, the choice of the pricing kernel $\left\{\pi^{*}\right\}$ serves the purpose of highlighting a point of definite interest for credit risk managers: The structure of the pricing kernel at unpredictable default, $\exp \left(\zeta^{*}\right) F^{*}\left(S_{t-}\right)$, implies substantial differences in the ways the objective default intensity and the risk-neutral intensity depend on equity markets. This is best seen by taking a constant objective intensity $\lambda_{\mathbb{P}}$ and a plausibly countercyclical risk premium on equity,

$$
\widehat{\mu_{\mathbb{P}}}\left(S_{t-}\right)-(r-q)=\kappa \cdot \sigma^{2} S_{t-}^{2(\rho-1)}, \quad 0<\kappa<1 .
$$

From Proposition (3), the variance-optimal pricing kernel hands over a riskneutral default intensity that is increasing in the diffusive local variance of equity returns:

$$
\widehat{\lambda_{\mathbb{Q}^{*}}}\left(S_{t-}\right)=\left(1+\frac{\kappa \cdot \sigma^{2} S_{t-}^{2(\rho-1)}}{\sigma^{2} S_{t-}^{2(\rho-1)}+\lambda_{\mathbb{P}}}\right) \lambda_{\mathbb{P}}
$$


This stylized example ${ }^{17}$ illustrates the empirical finding of Berndt, Douglas, Duffie, Ferguson, and Schranz (2005) that much of time variation in the riskneutral intensity comes from time variation in the jump-to-default risk price rather than from fluctuations in the objective intensity. They find dramatic equity-market-linked variation over time in the jump-to-default risk price, from peaks in the third quarter of 2002 to a significant drop by late 2003 after the bear market in global equities came to an end in March 2003.

A last remark is in order. The variance-optimal pricing kernel links the market price of diffusive risk with the market price of jump-to-default risk, so that the conditional expected return on equity becomes:

$$
\mu_{\mathbb{P}}\left(S_{t-}\right)-(r-q)=\left(\frac{\lambda_{\mathbb{Q}^{*}}\left(S_{t-}\right)}{\lambda_{\mathbb{P}}\left(S_{t-}\right)}-1\right)\left(\sigma^{2} S_{t-}^{2(\rho-1)}+\lambda_{\mathbb{P}}\left(S_{t-}\right)\right) .
$$

Hence, the intensities ratio implied by the variance-optimal pricing kernel can be read in the time-varying betas of a conditional constrained regression of excess stock returns on proxies for the diffusive local variance and for the objective intensity of default (the kernel choice constrains the time-varying betas of the two regressors to be equal).

\section{Consistency in risk management and pricing: A parsimonious model}

A parsimonious equity-based model that empowers analytical credit risk management as well as analytical pricing of credit-sensitive instruments is valuable. Thrifty formulae for the relevant items under $\mathbb{P}$ and under $\mathbb{Q}$ can be used to support, among other applications, a consistent and integrated filtering of information from the equity market, equity options markets, and from other credit-sensitive markets. Measurement-error issues are trimmed down by model's explicit focus on the underlying equity value, a clear market signal of corporate health.

\footnotetext{
${ }^{17}$ Notice that, since $\lambda_{\mathbb{Q}^{*}}\left(S_{t-}\right)$ is not a simple power function in the local variance, the asset-pricing facet of the example is not within the risk-neutral analysis of Carr and Linetsky (2006).
} 
Within our general model of Section 2, this is best done by considering the following parsimonious version of it. We take the $\mathbb{P}$-dynamics of the share price process $\{S\}$ to be

$$
\frac{\mathrm{d} S_{t}}{S_{t-}}=\left(\begin{array}{c}
r-q+ \\
\theta \sigma+ \\
\left(E^{\mathbb{P}}[\exp (\zeta)]-1\right) \lambda_{\mathbb{P}}
\end{array}\right) \mathrm{d} t+\sigma S_{t-}^{\rho-1} \mathrm{~d} z_{t}^{\mathbb{P}}-\left(\mathrm{d} N_{t}^{\mathbb{P}}-\lambda_{\mathbb{P}} \mathrm{d} t\right)
$$

with all the parameters constant. For the sake of simplicity, we assume that unpredictable default is always not liked by investors, that is, the pricing kernel's 'percentage jump' $\zeta$ is non-negative. This assumption can be relaxed at zero computational cost, since $\zeta$ can easily be either shifted downwards by adding a negative constant to it or taken with an opposite sign. The criterion of parameter parsimony suggests to take for $\zeta$ a one-parameter non-negative distribution. One such distribution is the discrete Poisson distribution with parameter $\phi(0<\phi<\infty)$ and with support $\{0,1,2, \ldots\}$, so that its quantities of interest admit a concise closed form,

$$
E^{\mathbb{P}}[\exp (\zeta)]=\exp (\phi(e-1))>1, \quad E^{\mathbb{P}}[\zeta]=\operatorname{Var}^{\mathbb{P}}[\zeta]=\phi .
$$

Helpfully, the systematic nature of the jump-to-default risk is turned off (the state-price density does not jump in the case of a jump to default) as the parameter $\phi$ is turned off $(\phi \downarrow 0$, that is, $\zeta=0 \mathbb{P}$-a. s.). An alternative parsimonious choice is the exponential distribution, whose absolute continuity with respect to the Lebesgue measure greatly enriches $\zeta$ 's support.

\subsection{Default probabilities}

Given a finite maturity $T$ (in years), $V^{\mathbb{P}}(S, T, 0)$ denotes the objective default probability,

$$
V^{\mathbb{P}}(S, T, y) \equiv E_{0}^{\mathbb{P}}\left[\exp (-y(\tau \wedge \xi)) \mathbf{1}_{\{\tau \wedge \xi \leq T\}}\right]
$$


being the $T$-truncated Laplace transform of $\tau \wedge \xi$ 's probability density function under $\mathbb{P}$ ( $\mathbb{P}$-p.d.f.) with Laplace parameter $y(y \geq 0)$. The next proposition is a useful result stemming from the independence between $\{z\}$ and $\{N\}$. It states that the quantity in Definition (4) is the linear convex combination of the adjusted objective probability of default within $T$ (with weight $\left.\frac{\lambda_{\mathbb{P}}}{y+\lambda_{\mathbb{P}}}\right)$ and of the $T$-truncated Laplace transform of $\xi^{c}$ 's $\mathbb{P}$-p.d.f. with Laplace parameter $y+\lambda_{\mathbb{P}}$ (with weight $\left.\frac{y}{y+\lambda_{\mathbb{P}}}\right)$.

Proposition 4 The quantity $V^{\mathbb{P}}(S, T, y)$ admits the following expression:

$$
\begin{aligned}
V^{\mathbb{P}}(S, T, y)= & \frac{\lambda_{\mathbb{P}}}{y+\lambda_{\mathbb{P}}}\left[1-\exp \left(-\left(y+\lambda_{\mathbb{P}}\right) T\right)\left(1-E_{0}^{\mathbb{P}}\left[\mathbf{1}_{\left\{\xi^{c} \leq T\right\}}\right]\right)\right]+ \\
& \frac{y}{y+\lambda_{\mathbb{P}}} E_{0}^{\mathbb{P}}\left[\exp \left(-\left(y+\lambda_{\mathbb{P}}\right) \xi^{c}\right) \mathbf{1}_{\left\{\xi^{c} \leq T\right\}},\right.
\end{aligned}
$$

Proof. See the Appendix. The T-truncated Laplace transform of $\xi^{c}$ 's $\mathbb{P}$-p.d.f. with Laplace parameter $w \geq 0$,

$$
E_{0}^{\mathbb{P}}\left[\exp \left(-(y+\lambda) \xi^{c}\right) \mathbf{1}_{\left\{\xi^{c} \leq T\right\}}\right]
$$

is analytical (see Campi and Sbuelz (2006)). Its closed form is also provided in the Appendix.

Equation (3) implies the following $\mathbb{Q}$-dynamics for $\{S\}$ :

$$
\begin{aligned}
\frac{\mathrm{d} S_{t}}{S_{t-}} & =(r-q) \mathrm{d} t+\sigma S_{t-}^{\rho-1} \mathrm{~d} z_{t}^{\mathbb{Q}}-\left(\mathrm{d} N_{t}^{\mathbb{Q}}-\lambda_{\mathbb{Q}} \mathrm{d} t\right), \\
z_{t}^{\mathbb{Q}} & \left.=z_{t}^{\mathbb{P}}+\int_{0}^{t} \theta S_{u-}^{1-\rho} \mathrm{d} u \quad \text { (Wiener process under } \mathbb{Q}\right), \\
\lambda_{\mathbb{Q}} & =\exp (\phi(e-1)) \lambda_{\mathbb{P}} .
\end{aligned}
$$

When the jump-like default risk is not systematic $(\phi \downarrow 0)$, the risk-neutral and objective jump-to-default intensities coincide. Let $V^{\mathbb{Q}}(S, T, y)$ be the $\mathbb{Q}$-counterpart of the truncated Laplace $\mathbb{P}$-transform $V^{\mathbb{P}}(S, T, y)$, that is,

$$
V^{\mathbb{Q}}(S, T, y) \equiv E_{0}^{\mathbb{Q}}\left[\exp (-y(\tau \wedge \xi)) \mathbf{1}_{\{\tau \wedge \xi \leq T\}}\right] .
$$


As long as diffusive risk and/or jump-to-default risk are systematic (with $\zeta \geq 0), V^{\mathbb{P}}(S, T, y)$ is always smaller than the quantity $V^{\mathbb{Q}}(S, T, y)$ for any $y$. In particular, systematic risk makes the $\mathbb{P}$-probability of default smaller than the $\mathbb{Q}$-probability of default. The technical reason is that the change of measure from $\mathbb{P}$ to $\mathbb{Q}$ leaves diffusive volatility unchanged but, while boosting the jump-to-default intensity $\left(\lambda_{\mathbb{Q}}>\lambda_{\mathbb{P}}\right)$, shrinks the away-from-zero drift of the stock price ${ }^{18}$ :

$$
r-q+\lambda_{\mathbb{Q}} \quad<\quad r-q+\theta \sigma+\lambda_{\mathbb{Q}}=\mu_{\mathbb{P}}+\lambda_{\mathbb{P}}
$$

The financial reason is that the state-price-embedding measure $\mathbb{Q}$ weighs dislikeable states more than the objective measure $\mathbb{P}$.

\subsection{Pricing instruments exposed to credit risk}

The quantity

$$
V^{\mathbb{Q}}(S, T, y) \equiv E_{0}^{\mathbb{Q}}\left[\exp (-y(\tau \wedge \xi)) \mathbf{1}_{\{\tau \wedge \xi \leq T\}}\right]
$$

is the building block for the analytical pricing of $T$-year-lived CBs and CDSs. $V^{\mathbb{Q}}(S, T, r)$ represents the fair present value of 1 unit of currency at the reference entity's default if default occurs within $T$. The next proposition gives an analytical characterization of $V^{\mathbb{Q}}(S, T, y)$. An alternative integral expression for $V^{\mathbb{Q}}(S, T, y)$ can be found by suitably specializing ${ }^{19}$ the Formula (5.15) in Carr and Linetsky (2006), p. 320.

Proposition 5 The T-truncated Laplace transform of $\tau \wedge \xi$ 's $\mathbb{Q}$-p.d.f. with Laplace parameter y can be expressed as:

$$
\begin{aligned}
V^{\mathbb{Q}}(S, T, y)= & \frac{\lambda_{\mathbb{Q}}}{y+\lambda_{\mathbb{Q}}}\left[1-\exp \left(-\left(y+\lambda_{\mathbb{Q}}\right) T\right)\left(1-E_{0}^{\mathbb{Q}}\left[\mathbf{1}_{\left\{\xi^{c} \leq T\right\}}\right]\right)\right] \\
& +\frac{y}{y+\lambda_{\mathbb{Q}}} E_{0}^{\mathbb{Q}}\left[\exp \left(-\left(y+\lambda_{\mathbb{Q}}\right) \xi^{c}\right) \mathbf{1}_{\left\{\xi^{c} \leq T\right\}}\right] .
\end{aligned}
$$

\footnotetext{
${ }^{18}$ More discussion on this point can be found, among others, in Duffie and Singleton (2003)

${ }^{19}$ The coefficient ' $c$ ' in Carr and Linetsky (2006), Equation (4.2), p. 311, must be set to zero.
} 
Proof. Since the risk-neutral drift $r-q+\lambda_{\mathbb{Q}}$ is constant, the proof is similar to that of Proposition (4). The $w$-discounted value of 1 unit of currency at the diffusive default within $T$,

$$
E_{0}^{\mathbb{Q}}\left[\exp \left(-w \cdot \xi^{c}\right) \mathbf{1}_{\left\{\xi^{c} \leq T\right\}}\right]
$$

is analytical ${ }^{20}$ (see Campi and Sbuelz (2006)).

Proposition (5) engenders analytical pricing of CBs and CDSs. Consider a reference entity's $\mathrm{CB}$ that has face value $F$ and pays an (annualized) coupon $C$ at regular $\frac{1}{k}$-spaced dates $T_{j}$ up to its maturity $T$ ( $k$ is a positive integer). We take the maturity $T$ to be a rational number of the type $\frac{n}{k}$ ( $n$ is also a positive integer) to keep notation simple.

Proposition 6 Given the recovery rate $R$ at default and given the assumption of Recovery of Face Value at Default (RFV), the fair CB price is

$$
\begin{aligned}
P_{C B}(S, T, r)= & \sum_{j=1}^{k T} \frac{1}{k} \exp \left(-r T_{j}\right)\left[1-V^{\mathbb{Q}}\left(S, T_{j}, 0\right)\right] C \\
& +\exp (-r T)\left[1-V^{\mathbb{Q}}(S, T, 0)\right] F \\
& +V^{\mathbb{Q}}(S, T, r) \cdot R \cdot F .
\end{aligned}
$$

Proof. The result comes from taking the $\mathbb{Q}$-expectation of CB's discounted payoffs. RFV bears the value $V^{\mathbb{Q}}(S, T, r) \cdot R \cdot F$ for CB's defaultable

\footnotetext{
${ }^{20}$ Davidov and Linetsky (2001) point out that the quantity $E_{0}^{\mathbb{Q}}\left[\exp \left(-w \xi^{c}\right) \mathbf{1}_{\left\{\xi^{c} \leq T\right\}}\right]$ can be obtained by numerically inverting the closed-form non-truncated Laplace transform

$$
\frac{1}{a} E_{0}^{\mathbb{Q}}\left[\exp \left(-(w+a) \xi^{c}\right)\right]
$$

where the inversion parameter is $a>0$, see pp. 953 and 956 . The same quantity has been also computed in Davydov and Linetsky (2003), Equation (155), p. 206, by means of a spectral expansion (the theory for such an expansion is thoroughly illustrated in Linetsky (2004)). The implementation of Equation (155) requires the numerical finding of the roots of a Whittaker function (see Equation (90), p. 193) in concert with the calculation of the limit ' $\lim _{L \downarrow 0}$ ', where $L$ is a lower price barrier $(L<S)$.
} 
part as it implies that the relevant discounted payoff is $\exp (-r(\tau \wedge \xi)) \mathbf{1}_{\{\tau \wedge \xi \leq T\}}$.

$R$ is a fixed historical data input in applications. Under RFV, CB holders receive the same fractional recovery $R$ of the face value $F$ at default for CBs issued by the reference entity regardless of maturity. Guha and Sbuelz (2005) show that the RFV recovery form is consistent with typical bond indenture language (for example, the claim acceleration clause), defaulted bond price data (same-seniority bonds exhibit the same market value at default regardless of maturity), and relevant stylized facts of non-defaulted bond price data (the low empirical duration of high-yield bonds; see Cornell and Green (1991) and Schaefer and Strebulaev (2006)).

Consider a CDS related to the CB just described. It offers a protection payment of $(1-R) F$ in exchange for an (annualized) fee $f_{C D S}$ paid at regular $\frac{1}{m}$-spaced dates up to the contract's maturity ( $m$ is a positive integer).

Proposition 7 The fair $C D S$ fee is

$$
f_{C D S}(S, T, r)=\frac{V^{\mathbb{Q}}(S, T, r)(1-R)}{\sum_{j=1}^{m T} \frac{1}{m} \exp \left(-r T_{j}\right)\left[1-V^{\mathbb{Q}}\left(S, T_{j}, 0\right)\right]} .
$$

Proof. Under $\mathbb{Q}$, the fee $f_{C D S}(S, T, r)$ makes the CDS' net present value equal to zero.

The holder of a $\mathrm{CB}$ can achieve total recouping of the face value $F$ at default by being long a CDS. Being short $\frac{\partial}{\partial S} P_{C B}(S, T, r)$ shares Delta-hedges ${ }^{21}$ against the pre-default price shocks driven by diffusive news. Recent empirical evidence shows that hedges based on equity portfolios perform reasonably well for high-yield CBs (see Naik, Trinh, Balakrishnan, and Sen (2003) and Schaefer and Strebulaev (2006)). Given analytical CB prices, an easy and

\footnotetext{
${ }^{21}$ The interest-rate sensitivity of bonds issued by non-high-credit-quality entities is kept quite subdued by the claim acceleration clause. In any case, parallel shifts of the (flat) term structure of the interest rates can be hedged by selling a portfolio of default-free bonds that has interest-rate sensitivity equal to $\frac{\partial}{\partial r} P_{C B}(S, T, r)$. Such a hedge ratio can be easily calculated in our model as $P_{C B}$ 's incremental ratio with respect to $r$.
} 
effective measure of the Delta-hedge ratio is $P_{C B}$ 's incremental ratio with respect to $S$. More details on model-based CB hedging are in the Appendix.

While extensive calibration ${ }^{22}$ is beyond the scope of the present work, a first interesting empirical test is the troubled market situation, as represented by stock prices and by reliable CDS quotes, of a big American air carrier like Delta Airline in the year 2002. Industry's long term problems emerged soon after the September 11th, 2001, terrorist attacks and the deep recession in air travel that followed. In addition, America's top airlines have suffered from huge pension obligations to retired employees and fierce competition from low-cost carriers. As Delta Airline's stock price dived from about $\$ 32$ in January 2002 to below $\$ 12$ by the end of December 2002, the term structure of annualized fees of quarterly CDSs was lifted from levels below 650 basis points to levels above the 1500 basis points and took a downward-sloping shape. Table 1 exhibits CDS market quotes ${ }^{23}$ and, in parentheses, the corresponding model-based quotes.

Table 1: CDS fees and share prices, Delta Airline (2002)

\begin{tabular}{ccccc}
\hline 1 -year & 2 -year & 3 -year & share price & Date \\
\hline 575.00 & 636.65 & 586.98 & & \\
$(586.51)$ & $(645.61)$ & $(626.79)$ & $\$ 32.18$ & $($ Jan. 4th, 2002) \\
& & & & \\
1979.42 & 1572.92 & 1503.58 & $\$ 11.90$ & $($ Dec. 18th, 2002) \\
$(2025.80)$ & $(1657.53)$ & $(1438.37)$ & & \\
& & & & \\
\hline
\end{tabular}

According to a distance-minimization criterion, the calibration of the modelimplied CDS-fee curve to the market curve has been performed by setting the elasticity of the diffusive volatility $\rho-1$ equal to -1.1 , the recovery

\footnotetext{
${ }^{22}$ For example, see Carr and Wu (2006).

${ }^{23}$ Data was provided by Fortis Bank, Brussels.
} 
rate $R$ equal to $65 \%$, and the risk-neutral intensity $\lambda_{\mathbb{Q}}$ equal to $\frac{1}{12.5}$. The parameter $\sigma$ has been chosen to reproduce the annualized volatility of daily percentage returns on the Delta stock over the last 3 months, which was $58 \%$ on January 4 th and $115 \%$ on December 18 th. The other parameters are $r=4.25 \%$ (close to the average midpoint of the term structure of US defaultfree interest rates over the year 2002) and $q=0$. Although parsimonious, the model seems flexible in capturing levels and shapes of CDS fees that come along with significative states of equity market valuation.

As CDS markets have been growing by leaps and bounds, reliable quotes can be currently gathered for maturities up to 10 years and the shape of CDS-fee term structures can be confidently measured for the 1-to-10-year maturity span. In our last empirical test, the model does show goodness of fit to different patterns of curve steepness. We consider recent Bloomberg data on two American giants of the car industry, which has not been unfamiliar with distress in recent years. For Ford, Table 2 exhibits CDS quotes and, in parentheses, the corresponding model-based quotes.

Table 2: CDS fees and share price, Ford (December 2nd, 2006)

\begin{tabular}{cccccc}
\hline 1 -year & 3 -year & 5 -year & 7 -year & 10 -year & share price \\
\hline & & & & & \\
145.00 & 405.50 & 534.75 & 572.00 & 584.25 & $\$ 8.04$ \\
$(181.41)$ & $(411.51)$ & $(536.33)$ & $(572.84)$ & $(584.08)$ & \\
& & & & & \\
\hline
\end{tabular}

The calibration of the model-implied CDS-fee curve to the market curve has been implemented by fixing $\rho-1=-0.22, R=65 \%$, and $\lambda_{\mathbb{Q}}=\frac{1}{20}$. The parameter $\sigma$ has been chosen to yield a diffusive volatility of $105 \%$. The other parameters are $r=5.25 \%$ (about the midpoint of the term structure of US default-free interest rates at the beginning of December 2006) and $q=0$. The model is able to match the marked steepness at short maturities and fits well the 5-to-10 year curve. Table 3 exhibits the case of General 
Motor.

Table 3: CDS fees and share price, General Motor (December 2nd, 2006)

\begin{tabular}{cccccc}
\hline $1-$ year & 3 -year & 5 -year & 7 -year & 10 -year & share price \\
\hline & & & & & \\
130.00 & 296.25 & 404.92 & 443.50 & 463.50 & $\$ 29.85$ \\
$(142.55)$ & $(287.64)$ & $(406.25)$ & $(449.53)$ & $(467.39)$ & \\
& & & & & \\
\hline
\end{tabular}

Calibration has been achieved by taking $\rho-1=-0.225, R=65 \%$, and $\lambda_{\mathbb{Q}}=\frac{1}{25}$. The parameter $\sigma$ has been chosen to yield a diffusive volatility of $95 \%$. The other parameters are $r=5.25 \%$ and $q=0$. The goodness of fit is fine also in this case. In summary, these empirical pricing tests show that thrift has empowered the model with analytical results without jeopardizing its flexibility.'

\section{Conclusions}

We present an equity-based credit risk model that, by taking as primitive the most liquid and observable part of a firm's capital structure, departs from reduced-form models and overcomes many of the problems suffered by structural models in credit-risk management, pricing, and hedging applications. We study systematic credit risk via an explicit modelling of risk premia. This brings an economic and technical contribution to the current literature on equity-based jump-to-default credit risk, which, focused on pricing-measure concerns, has not been dealing with the economic and technical treatment of risk premia and of default risk premia in particular. Technically, we prove that the pricing kernels we study do support equivalent martingale measures, also in unexplored but credit-risk-relevant regions of the parameters. Economically, we show that sensible pricing kernels for hedgers can be consistent with mounting empirical evidence that the jumpto-default risk price heavily loads equity market fluctuations, reaching highs 
during bear equity markets. A conceivable conjecture is that bear equity markets might, among other things, exacerbate the propensity to be hedged against default risk even if the increase of such a risk is only marginal. We then discuss a parsimonious version of our general model that uses the same technical steps to support analytical credit-risk management as well as analytical pricing of credit-sensitive instruments. Empirical tests show that parsimony enriches the model with analytical results without jeopardizing its flexibility.

As the equity price is becoming a popular measure of the 'dollar' distance to default, we believe that future research can capitalize with avail on our model to investigate credit risk issues that reach over different securities (equity and other credit-sensitive instruments) and over different applications (risk management, pricing, and hedging). 


\section{$5 \quad$ Appendix}

\section{Proof of Proposition (2)}

We will use the following auxiliary result.

Lemma 8 Let $\rho<1$, so possibly taking negative values, let $S^{c}$ be the continuous part of $S$ with $\mathbb{P}$-dynamics

$$
\frac{\mathrm{d} S_{t}^{c}}{S_{t}^{c}}=\left(r-q+\theta\left(S_{t}^{c}\right) \sigma+\lambda_{\mathbb{P}}\left(S_{t}^{c}\right)\right) \mathrm{d} t+\sigma\left(S_{t}^{c}\right)^{\rho-1} \mathrm{~d} z_{t}^{\mathbb{P}},
$$

and let $\eta_{t}$ be defined as follows:

$$
\eta_{t} \equiv \mathcal{E}\left(-\int_{0}^{\cdot} \theta\left(S_{t}^{c}\right)\left(S_{u}^{c}\right)^{1-\rho} \mathrm{d} z_{u}^{\mathbb{P}}\right)_{t}, \quad t \geq 0
$$

Then, for any $0<T<\infty,\{\eta\}$ is a true $\mathbb{P}$-martingale over $[0, T]$. In particular, $E_{0}^{\mathbb{P}}\left[\eta_{T}\right]=1$.

Proof. Following the proof of Theorem 2.3 in Delbaen and Shirakawa (2002), the crucial argument for $\eta_{t}$ to be a true $\mathbb{P}$-martingale is that the integral $\int_{0}^{T} \theta\left(S_{t}^{c}\right)^{2}\left(S_{u}^{c}\right)^{2(1-\rho)} \mathrm{d} u$ is finite a.s.. Delbaen and Shirakawa (2002) show that this is the case for $\rho \in(0,1)$. We notice that this integral remains finite a.s. even for $\rho \leq 0$. Indeed, since the function $\theta(\cdot)$ is bounded and $S^{c}$ has continuous trajectories, the integral cannot explode.

To simplify the notation, we set $\widetilde{\pi}_{t} \equiv e^{r t} \pi_{t}$. From Proposition (1) stating $\{\pi\}$ 's $\mathbb{P}$-dynamics, it follows that for $t<\tau \wedge \xi$

$\frac{\mathrm{d} \widetilde{\pi}_{t}}{\widetilde{\pi}_{t-}}=-\theta\left(S_{t-}\right) S_{t-}^{1-\rho} \mathrm{d} z_{t}^{\mathbb{P}}+\left(\left(e^{\zeta} F\left(S_{t-}\right)-1\right) \mathrm{d} N_{t}^{\mathbb{P}}-\left(E_{0}^{\mathbb{P}}\left[e^{\zeta}\right] F\left(S_{t-}\right)-1\right) \lambda_{\mathbb{P}}\left(S_{t-}\right)\right) \mathrm{d} t$, and $\tilde{\pi}_{t}=\tilde{\pi}_{\tau \wedge \xi}$ for $t \geq \tau \wedge \xi$. The initial condition is of course $\widetilde{\pi}_{0}=1$. We can write the process $\widetilde{\pi}_{t}$ as a Doléans-Dade stochastic exponential (see, e.g., Protter (1990), p. 78) in the following way:

$$
\tilde{\pi}_{t}=\mathcal{E}\left(-\int_{0}^{\cdot} \theta\left(S_{u-}\right) S_{u-}^{1-\rho} \mathrm{d} z_{u}^{\mathbb{P}}\right)_{t \wedge \tau \wedge \xi} Y_{t \wedge \tau \wedge \xi},
$$


where we set

$Y_{t}=\exp \left\{\sum_{u \leq t} \ln \left(1+\left(e^{\zeta} F\left(S_{u-}\right)-1\right) \Delta N_{u}^{\mathbb{P}}\right)-\int_{0}^{t}\left(E_{0}^{\mathbb{P}}\left[e^{\zeta}\right] F\left(S_{u-}\right)-1\right) \lambda_{\mathbb{P}}\left(S_{u-}\right) \mathrm{d} u\right\}$.

Fix a finite time horizon $T>0$. We first prove that the process

$$
\mathcal{E}\left(-\int_{0}^{\cdot} \theta\left(S_{u-}\right) S_{u-}^{1-\rho} \mathrm{d} z_{u}^{\mathbb{P}}\right)_{t \wedge \tau \wedge T} Y_{t \wedge \tau \wedge T}, \quad t \geq 0
$$

is a $\mathbb{P}$-martingale. Being the stochastic exponential of a local $\mathbb{P}$-martingale, it is a local $\mathbb{P}$-martingale itself.

To show that it is a $\mathbb{P}$-martingale, it suffices to prove that

$$
\Psi:=E_{0}^{\mathbb{P}}\left[\mathcal{E}\left(-\int \theta S_{u-}^{1-\rho} \mathrm{d} z_{u}^{\mathbb{P}}\right)_{\tau \wedge T} Y_{\tau \wedge T}\right]<\infty .
$$

First, note that, in the stochastic exponential containing the Brownian part, i.e. $\mathcal{E}\left(-\int_{0}^{\cdot} \theta\left(S_{u-}\right) S_{u-}^{1-\rho} \mathrm{d} z_{u}^{\mathbb{P}}\right)_{t \wedge \tau \wedge T}$, we can replace the process $S$ with its continuous part $S^{c}$, which is independent of $N^{\mathbb{P}}$ and $\zeta$ by construction and has dynamics (6). Conditioning with respect to $\zeta$ gives

$E_{0}^{\mathbb{P}}\left[\mathcal{E}\left(-\int_{0}^{\cdot} \theta\left(S_{u-}\right) S_{u-}^{1-\rho} \mathrm{d} z_{u}^{\mathbb{P}}\right)_{\tau \wedge T} Y_{\tau \wedge T}\right]=E_{0}^{\mathbb{P}}\left[\mathcal{E}\left(-\int_{0}^{\cdot} \theta\left(S_{u-}\right)\left(S_{u-}^{c}\right)^{1-\rho} \mathrm{d} z_{u}^{\mathbb{P}}\right)_{\tau \wedge T} \tilde{Y}_{\tau \wedge T}\right]$,

where $\tilde{Y}$ is the process $Y$ after replacing $e^{\zeta}$ with its expectation $E_{0}^{\mathbb{P}}\left[e^{\zeta}\right]$, so that

$\widetilde{Y}_{\tau \wedge T}=\left(1+\left(E_{0}^{\mathbb{P}}\left[e^{\zeta}\right] F\left(S_{\tau \wedge T}^{c}\right)-1\right) \mathbf{1}_{\{\tau \leq T\}}\right) \exp \left\{-\left(E_{0}^{\mathbb{P}}\left[e^{\zeta}\right] F\left(S_{\tau \wedge T}^{c}\right)-1\right) \int_{0}^{\tau \wedge T} \lambda_{\mathbb{P}}\left(S_{u}^{c}\right) \mathrm{d} u\right\}$.

Since the functions $F$ and $\lambda^{\mathbb{P}}$ are positive and bounded, one has

$$
1+\left(E_{0}^{\mathbb{P}}\left[e^{\zeta}\right] F\left(S_{\tau \wedge T}^{c}\right)-1\right) \mathbf{1}_{\{\tau \leq T\}} \leq C
$$

for some positive constant $C$. Moreover, being $F(\cdot) \geq 1, \zeta \geq 0$ and $\lambda_{\mathbb{P}}(\cdot) \geq 0$ we also have

$$
\exp \left\{-\left(E_{0}^{\mathbb{P}}\left[e^{\zeta}\right] F\left(S_{\tau \wedge T}^{c}\right)-1\right) \int_{0}^{\tau \wedge T} \lambda_{\mathbb{P}}\left(S_{u}^{c}\right) \mathrm{d} u\right\} \leq 1
$$


so giving

$$
\Psi \leq C E_{0}^{\mathbb{P}}\left[\mathcal{E}\left(-\int_{0}^{\cdot} \theta\left(S_{u-}\right)\left(S_{u-}^{c}\right)^{1-\rho} \mathrm{d} z_{u}^{\mathbb{P}}\right)_{\tau \wedge T}\right] .
$$

An application of Lemma 8 gives

$$
\begin{aligned}
\Psi & \leq C E_{0}^{\mathbb{P}}\left[\mathcal{E}\left(-\int_{0}^{\cdot} \theta\left(S_{u-}^{c}\right)\left(S_{u-}^{c}\right)^{1-\rho} \mathrm{d} z_{u}^{\mathbb{P}}\right)_{\tau \wedge T}\right] \\
& =C<\infty
\end{aligned}
$$

This yields that $\mathcal{E}\left(-\int \theta\left(S_{u-}\right) S_{u-}^{1-\rho} \mathrm{d} z_{u}^{\mathbb{P}}\right)_{t \wedge \tau \wedge T} Y_{t \wedge \tau \wedge T}$ is a $\mathbb{P}$-martingale. Doob's optional sampling theorem applies (e.g., Theorem 18 in Protter (1990)) so that the process $\tilde{\pi}_{t}$ is a $\mathbb{P}$-martingale over the time interval $[0, T]$. Being $T$ arbitrary, the proof is now complete.

\section{Proof of Proposition (4)}

We have that

$$
\begin{aligned}
\mathbb{P}_{0}[\tau \wedge \xi>s] & =\mathbb{P}_{0}[\tau>s, \xi>s] \\
& =E_{0}^{\mathbb{P}}\left[\mathbf{1}_{\{\tau>s\}} \mathbb{P}_{0}\left[\xi>s \mid N_{u}=0, u \leq s\right]\right] \\
& =E_{0}^{\mathbb{P}}\left[\mathbf{1}_{\{\tau>s\}} \mathbb{P}_{0}\left[\xi^{c}>s \mid N_{u}=0, u \leq s\right]\right] \\
& =\mathbb{P}_{0}[\tau>s] \mathbb{P}_{0}\left[\xi^{c}>s\right],
\end{aligned}
$$

where the last equality follows from the independence between $\xi^{c}$ and $\tau$. Hence, the time-s-evaluated $\mathbb{P}$-p.d.f. of the stopping time $\tau \wedge \xi$ is

$$
\begin{aligned}
f_{\tau \wedge \xi}(s) & =-\frac{\mathrm{d}}{\mathrm{d} s} \mathbb{P}_{0}[\tau \wedge \xi>s] \\
& =-\frac{\mathrm{d}}{\mathrm{d} s}\left(\mathbb{P}_{0}[\tau>s] \mathbb{P}_{0}\left[\xi^{c}>s\right]\right) \\
& =f_{\tau}(s) \mathbb{P}_{0}\left[\xi^{c}>s\right]+f_{\xi^{c}}(s) \mathbb{P}_{0}[\tau>s] \\
& =\lambda \exp (-\lambda s) \mathbb{P}\left[\xi^{c}>s\right]+f_{\xi^{c}}(s) \exp (-\lambda s) .
\end{aligned}
$$


By Definition (4), the $T$-truncated Laplace transform of $\tau \wedge \xi$ 's $\mathbb{P}$-p.d.f. with Laplace parameter $y$ is

$$
\begin{array}{r}
V^{\mathbb{P}}(S, T, y)=\int_{0}^{T} \exp (-y s) f_{\tau \wedge \xi}(s) \mathrm{d} s \\
=\int_{0}^{T} \exp (-y s) f_{\tau \wedge \xi^{c}}(s) \mathrm{d} s \\
=\lambda Y_{1}+Y_{2}, \\
Y_{1}=\int_{0}^{T} \exp (-(y+\lambda) s) \mathbb{P}_{0}\left[\xi^{c}>s\right] \mathrm{d} s, \\
Y_{2}=\int_{0}^{T} \exp (-(y+\lambda) s) f_{\xi^{c}}(s) \mathrm{d} s .
\end{array}
$$

$Y_{2}$ is the $T$-truncated Laplace transform of $\xi^{c}$ s $\mathbb{P}$-p.d.f. with Laplace parameter $y+\lambda$,

$$
Y_{2}=E_{0}^{\mathbb{P}}\left[\exp \left(-(y+\lambda) \xi^{c}\right) \mathbf{1}_{\left\{\xi^{c} \leq T\right\}}\right]
$$

Its closed form has been derived by Campi and Sbuelz (2006) and it can be found below after this proof. An integration by parts gives

$$
\begin{aligned}
Y_{1}= & \left.\frac{-1}{y+\lambda} \exp (-(y+\lambda) s) \mathbb{P}_{0}\left[\xi^{c}>s\right]\right|_{0} ^{T} \\
& -\int_{0}^{T} \frac{-1}{y+\lambda} \exp (-(y+\lambda) s)\left(-f_{\xi^{c}}(s)\right) \mathrm{d} s \\
= & \frac{1}{y+\lambda}\left[1-\exp (-(y+\lambda) T) \mathbb{P}_{0}\left[\xi^{c}>T\right]\right]-\frac{1}{y+\lambda} Y_{2} .
\end{aligned}
$$

This completes the proof.

\section{The objective probability of default at $\xi^{c}$ within $T$}

The continuous-path process $\left\{\xi^{c}\right\}$ has the following $\mathbb{P}$-dynamics:

$$
\frac{\mathrm{d} S_{t}^{c}}{S_{t}^{c}}=\left(\mu_{\mathbb{P}}+\lambda_{\mathbb{P}}\right) \mathrm{d} t+\sigma\left(S_{t}^{c}\right)^{\rho-1} \mathrm{~d} z_{t}^{\mathbb{P}} .
$$


Campi and Sbuelz (2006) have shown that the $T$-truncated Laplace transform of $\xi^{c}$ s $\mathbb{P}$-p.d.f. with Laplace parameter $w(w \geq 0)$ has this analytical expression:

$$
E_{0}^{\mathbb{P}}\left[\exp \left(-w \xi^{c}\right) \mathbf{1}_{\left\{\xi^{c} \leq T\right\}}\right]=\lim _{\epsilon \downarrow 0} \sum_{n=0}^{\infty} a_{n}\left(A_{\mathbb{P}}, B_{\mathbb{P}}\right)\left(\frac{x}{2}\right)^{n} \frac{\Gamma\left(\nu-n, \frac{x}{2 K_{\mathbb{P}}}, \frac{x}{2 \epsilon}\right)}{\Gamma(\nu)}
$$

for

$$
\begin{array}{rlr}
\Gamma(\nu) & \equiv \int_{0}^{+\infty} u^{\nu-1} e^{-u} \mathrm{~d} u & \text { (Gamma Function) } \\
\Gamma\left(\nu-n, \frac{x}{2 K_{\mathbb{P}}}, \frac{x}{2 \epsilon}\right) & \equiv \int_{\frac{x}{2 K_{\mathbb{P}}}}^{\frac{x}{2 \epsilon}} u^{-n} u^{\nu-1} e^{-u} \mathrm{~d} u & \text { (Generalized Incomplete Gamma Function) } \\
a_{n}\left(A_{\mathbb{P}}, B_{\mathbb{P}}\right) & \equiv(-1)^{n} C\left(B_{\mathbb{P}}, n\right) A_{\mathbb{P}}^{n} \\
C\left(B_{\mathbb{P}}, n\right) & \equiv \frac{\prod_{k=1}^{n}\left(B_{\mathbb{P}}-(k-1)\right)}{n !} \mathbf{1}_{\{n \geq 1\}}+\mathbf{1}_{\{n=0\}},
\end{array}
$$

and

$$
\begin{aligned}
x & \equiv S^{2(1-\rho)}, \quad \nu \equiv \frac{1}{2(1-\rho)}, \\
A_{\mathbb{P}} & \equiv \frac{2\left(\mu_{\mathbb{P}}+\lambda_{\mathbb{P}}\right)}{\sigma^{2}(1-\rho)}, \quad K_{\mathbb{P}} \equiv \frac{\sigma^{2}(1-\rho)}{2\left(\mu_{\mathbb{P}}+\lambda_{\mathbb{P}}\right)}\left(1-e^{-2 T\left(\mu_{\mathbb{P}}+\lambda_{\mathbb{P}}\right)(1-\rho)}\right) \\
B_{\mathbb{P}} & \equiv \frac{w}{2\left(\mu_{\mathbb{P}}+\lambda_{\mathbb{P}}\right)(1-\rho)} .
\end{aligned}
$$

Notice that the limit ' $\lim _{\epsilon \downarrow}$ ' can be exchanged with the $\operatorname{limit}^{\prime} \lim _{m \uparrow \infty} \sum_{n=0}^{m}$ ', that is, the first limit can be brought inside the infinite summation and computed in closed form term by term. This is because the origin is a 
limit point for the set $\left(0, K_{\mathbb{P}}\right]$ and the series $\sum_{n=0}^{\infty} f_{n}(\epsilon)$ enjoys uniform convergence on the set $\left(0, K_{\mathbb{P}}\right]$, with

$$
f_{n}(\epsilon)=a_{n}\left(A_{\mathbb{P}}, B_{\mathbb{P}}\right)\left(\frac{x}{2}\right)^{n} \frac{\Gamma\left(\nu-n, \frac{x}{2 K_{\mathbb{P}}}, \frac{x}{2 \epsilon}\right)}{\Gamma(\nu)} .
$$

To see this, notice that $\left|f_{n}(\epsilon)\right|$ is bounded for $\nu-n>0$. For $\nu-n<0$, start with observing that

$$
\begin{aligned}
\int_{\frac{x}{2 K_{\mathbb{P}}}}^{\frac{x}{2 \epsilon}} u^{\nu-n-1} e^{-u} \mathrm{~d} u & <\int_{\frac{x}{2 K_{\mathbb{P}}}}^{\infty} u^{\nu-n-1} \mathrm{~d} u \\
& =\left(\frac{x}{2 K_{\mathbb{P}}}\right)^{\nu-n} \frac{(-1)}{\nu-n} .
\end{aligned}
$$

Consider now the following $\epsilon$-independent majoration for $\left|f_{n}(\epsilon)\right|$ :

$$
\begin{aligned}
\left|f_{n}(\epsilon)\right| & <\frac{1}{\Gamma(\nu)} \max \left(B_{\mathbb{P}}^{2}, 1\right) A_{\mathbb{P}}^{n}\left(\frac{x}{2}\right)^{n}\left(\frac{x}{2 K_{\mathbb{P}}}\right)^{\nu-n} \frac{(-1)}{\nu-n} \\
& <\frac{1}{\Gamma(\nu)} \max \left(B_{\mathbb{P}}^{2}, 1\right)\left(A_{\mathbb{P}} K_{\mathbb{P}}\right)^{n}\left(\frac{x}{2 K_{\mathbb{P}}}\right)^{\nu} \frac{(-1)}{\nu-n} \\
& =g_{n} .
\end{aligned}
$$

By construction, $A_{\mathbb{P}} K_{\mathbb{P}}$ is positive and smaller than unity and the series $\sum_{n=0}^{\infty} g_{n}$ converges. It follows that

$$
\begin{aligned}
E_{0}^{\mathbb{P}}\left[\exp \left(-w \xi^{c}\right) \mathbf{1}_{\left\{\xi^{c} \leq T\right\}}\right] & =\sum_{n=0}^{\infty} a_{n}\left(A_{\mathbb{P}}, B_{\mathbb{P}}\right)\left(\frac{x}{2}\right)^{n} \frac{\Gamma\left(\nu-n, \frac{x}{2 K_{\mathbb{P}}}\right)}{\Gamma(\nu)} \\
\Gamma\left(\nu-n, \frac{x}{2 K_{\mathbb{P}}}\right) & \equiv \int_{\frac{x}{2 K_{\mathbb{P}}}}^{\infty} u^{-n} u^{\nu-1} e^{-u} \mathrm{~d} u \quad \text { (Incomplete Gamma Function) } .
\end{aligned}
$$


The Incomplete Gamma Function and the Gamma function are builtin routines in many computing software like MATLAB and Mathematica, which makes the above expressions fully viable. The analytical expression of the objective probability of diffusive default within time $T$ is retrieved by taking $w=0$.

The discounted value of cash at $\xi^{c}$ within $T$

The replacement of the objective drift $\mu_{\mathbb{P}}+\lambda_{\mathbb{P}}$ with the risk-neutral drift $r-q+\lambda_{\mathbb{Q}}$ in the formula for the $T$-truncated Laplace transform of $\xi^{c}$ 's p.d.f. with Laplace parameter $w(w \geq 0)$ implies that the discounted value of cash at $\xi^{c}$ within $T$ is

$$
E_{0}^{\mathbb{Q}}\left[\exp \left(-w \cdot \xi^{c}\right) \mathbf{1}_{\left\{\xi^{c} \leq T\right\}}\right]=\sum_{n=0}^{\infty} a_{n}(A, B)\left(\frac{x}{2}\right)^{n} \frac{\Gamma\left(\nu-n, \frac{x}{2 K}\right)}{\Gamma(\nu)}
$$

where

$$
\begin{aligned}
A & \equiv \frac{2\left(r-q+\lambda_{\mathbb{Q}}\right)}{\sigma^{2}(1-\rho)}, \quad K \equiv \frac{\sigma^{2}(1-\rho)}{2\left(r-q+\lambda_{\mathbb{Q}}\right)}\left(1-e^{-2 T\left(r-q+\lambda_{\mathbb{Q}}\right)(1-\rho)}\right) \\
B & \equiv \frac{w}{2\left(r-q+\lambda_{\mathbb{Q}}\right)(1-\rho)}
\end{aligned}
$$

\section{The CEV model and time-dependent coefficients}

In the standard CEV model (i.e. without jumps, $\lambda_{\mathbb{P}} \downarrow 0$ ), Campi and Sbuelz (2006) obtain an explicit formula for $\xi^{c}$ 's truncated Laplace transform via the identity in law (2.7) in Delbaen and Shirakawa (2002). Using similar 
arguments and defining

$$
m(t)=\left\{\begin{array}{ccc}
\mu_{\mathbb{P}}(t) & \text { under } & \mathbb{P}, \\
r(t)-q(t) & \text { under } & \mathbb{Q},
\end{array}\right.
$$

one can extend such an identity to the case of time-dependent coefficients, so that the following time-changed process

$$
e^{\int_{0}^{t} m(s) \mathrm{d} s}\left(|\rho| X_{\tau_{t}}^{(2(1-\nu))}\right)^{1 /|\rho|}, \quad t \geq 0,
$$

has the same law as the CEV process with time-dependent coefficients $m(t)$ and $\sigma(t)$, where $X_{t}^{(\delta)}$ is a $\delta$-dimensional squared Bessel process and the deterministic time-change $\tau_{t}$ is

$$
\tau_{t}=\int_{0}^{t} \sigma(s)^{2} e^{-|\rho| \int_{0}^{s} m(u) \mathrm{d} u} \mathrm{~d} s, \quad t \geq 0 .
$$

The mentioned identity in law implies the following relation between $\xi^{c}$ and $\widehat{\xi}=\inf \left\{s: X_{s}^{(2(\nu-1))}=0\right\}$ :

$$
\widehat{\xi}=\int_{0}^{\xi^{c}} \sigma^{2}(s) e^{-2|\rho| \int_{0}^{s} m(u) \mathrm{d} u} \mathrm{~d} s .
$$

Unfortunately, the complex non-linearity of the above relation can hardly be unravelled, so that $\xi^{c}$ cannot be be expressed as an explicit function of $\widehat{\xi}$. This is true even when, e.g. under $\mathbb{Q}, \sigma$ and $q$ are constant and the interest rate $r(t)$ is linear in $t$.

\section{Model-based CB hedging}

Full dynamic hedging of a long position in a CB (with recovery rate $R$ and face value $F$ ) implies being short $\eta$ units of stocks as well as being long $\xi$ units of CDSs with given fee $f$ (for recovery rate $Z$ and notional $X$ ), where $\eta$ and $\xi$ are adapted processes that satisfy the following system of risk-exposure-nullifying equations:

$$
\left\{\begin{aligned}
\frac{\partial}{\partial S} P_{C B}-\eta+\xi \frac{\partial}{\partial S} H(S, T, r) & =0 \\
R \cdot F-P_{C B}(S, T, r)-\eta(-S)+\xi[(1-Z) X-H(S, T, r)] & =0
\end{aligned}\right.
$$


with $H(S, T, r)$ being the fair present value of a long CDS position:

$H(S, T, r) \equiv V^{\mathbb{Q}}(S, T, r)(1-Z) X-\sum_{j=1}^{m T} \frac{1}{m} \exp \left(-r T_{j}\right)\left[1-V^{\mathbb{Q}}\left(S, T_{j}, 0\right)\right] f$

Our model also states that, in the case of a jump to default $(\tau \wedge \xi=\tau)$, pure Delta hedging recoups a fraction

$$
\frac{\frac{\partial}{\partial S} P_{C B}\left(S_{\tau-}, T-\tau^{-}, r\right) S_{\tau-}}{P_{C B}\left(S_{\tau-}, T-\tau^{-}, r\right)-R \cdot F}
$$

of the CB loss suffered at default. 


\section{References}

[1] Acharya, V., and J. Carpenter (2002): Corporate bond valuation and hedging with stochastic interest rates and endogenous bankruptcy, Review of Financial Studies 15, pp. 1355-1383.

[2] Albanese, C., J. Campolieti, P. Carr, and A. Lipton (2001): BlackScholes Goes Hypergeometric, Risk Magazine, 14, pp. 99-103.

[3] Albanese, C. and O. Chen (2005). Pricing equity default swaps. Risk Magazine, 18, pp. 83-87.

[4] Andersen, L. and J. Andreasen (2000): Jump-Diffusion Processes: Volatility Smile Fitting and Numerical Methods for Pricing, Review of Derivatives Research, 4 (3), pp. 231-262.

[5] Andersen, L. and D. Buffum (2003): Calibration and Implementation of Convertible Bond Models, Journal of Computational Finance, 7 (2), pp. 1-34.

[6] Beckers, S., (1980): The Constant Elasticity of Variance Model and its Implications for Option Pricing, Journal of Finance, 35, 661-73.

[7] Bellamy, N., and M. Jeanblanc (2000): Incompleteness of markets driven by a mixed diffusion, Finance and Stochastics, 4, pp. 209-222.

[8] Berndt, A., Douglas, R., Duffie, D., Ferguson, M., and D. Schranz (2005): Measuring Default Risk Premia from Default Swap Rates and EDFs, Working paper, Carnegie Mellon University.

[9] Berndt A., Lookman A., and I. Obreja (2006): Default Risk Premia and Asset Returns, Working paper, Carnegie Mellon University.

[10] Bertsimas, D., Kogan, L., and A. Lo (2001), Hedging Derivative Securities and Incomplete Markets: An $\varepsilon$-Arbitrage Approach, Operations Research, 49 (3), pp. 372-397. 
[11] Biagini F., and A. Cretarola (2005): Quadratic hedging methods for defaultable claims, preprint, Mathematics Institute, University of $\mathrm{Mu}-$ nich.

[12] Biagini F., and A. Cretarola (2006): Local Risk-Minimisation for Defaultable Markets, preprint, Mathematics Institute, University of $\mathrm{Mu}-$ nich.

[13] Bielecki, T.R., Jeanblanc, M., and M. Rutkowski (2004a): Hedging of defaultable claims, Paris-Princeton Series, Lecture notes in mathematical finance, Springer.

[14] Bielecki T.R., Jeanblanc M., and M. Rutkowski (2004b): Pricing and Hedging of Credit Risk: Replication and Mean- Variance Approaches I, Mathematics of Finance, Contemp. Math., 351, Amer. Math. Soc., Providence, RI, pp. 37-53.

[15] Bielecki T.R., Jeanblanc M., and M. Rutkowski (2004c): Pricing and Hedging of Credit Risk: Replication and Mean- Variance Approaches II, Mathematics of Finance, Contemp. Math., 351, Amer. Math. Soc., Providence, RI, pp. 55-64.

[16] Bielecki T.R., Jeanblanc M., and M. Rutkowski (2004d): Hedging of Defaultable Claims, Paris-Princeton Lectures on Mathematical Finance 2003, Lecture Notes in Mathematics 1847, Springer, Berlin.

[17] Black, F. (1976): Studies of Stock Price Volatility Changes, Proceedings of the 1976 American Statistical Association, Business and Economical Statistics Section, American Statistical Association, Alexandria, VA, pp. $177-181$.

[18] Black, F. and J. Cox ( 1976): Valuing Corporate Securities: Some Effects of Bond Indenture Provisions, Journal of Finance, 31, 351-367. 
[19] Blanchet-Scaillet, C., N. El Karoui, and L. Martellini (2005): Dynamic asset pricing theory with uncertain time-horizon, Journal of Economic Dynamic and Control, 29 (10), pp. 1737-1764.

[20] Boyle,P.P., and Y.Tian (1999): Pricing lookback and barrier options under the CEV process, Journal of Financial and Quantitative Analyis, 34 (Correction: P.P. Boyle, Y. Tian, J. Imai. Lookback options under the CEV process: A correction. JFQA web site at http://depts.washington.edu/jfqa/ in Notes, comments, and corrections).

[21] Brigo, D., and M. Tarenghi (2005a): Credit Default Swap Calibration and Equity Swap Valuation under Counterparty Risk with a Tractable Structural Model, Reduced version in Proceedings of the FEA 2004 Conference at MIT, Cambridge, Massachusetts, November 8-10.

[22] Brigo, D., and M. Tarenghi (2005b): Credit Default Swap Calibration and Counterparty Risk Valuation with a Scenario based First Passage Model, ICBI's Global Derivatives \& Risk Managment Conference2005, Paris, May 23-26.

[23] Brigo, D., and M. Morini (2006): CDS Market Formulas and Models (Structural credit calibration), Risk Magazine, 19, April.

[24] Campi, L., and A. Sbuelz (2006): Closed-form pricing of Benchmark Equity Default Swaps under the CEV assumption, Risk Letters, 1(3), http://www.globalecofinance.com/Article.aspx?i=48.

[25] Carr, P., and V. Linetsky (2006): A Jump to Default Extended CEV Model: An Application of Bessel Processes, Finance and Stochastics, vol. 10, pp. 303-330.

[26] Carr, P., and L. Wu (2006): Stock Options and Credit Default Swaps: A Joint Framework for Valuation and Estimation, http://ssrn.com/abstract $=748005$. 
[27] Cathcart, L. and L. El-Jahel (2003): Semi-analytical pricing of defaultable bonds in a signaling jump-default model, Journal of Computational Finance, Vol. 6, pp. 91-108.

[28] Cornell, B., and K. Green (1991): The investment performance of lowgrade bond funds, Journal of Finance 46, pp. 29-47.

[29] Cox, J. (1975): Notes on option pricing I: constant elasticity of variance diffusions. Working paper, Stanford University (reprinted in Journal of Portfolio Management, 1996, 22, 15-17).

[30] Cox, J., and S. Ross (1976): The Valuation of Options for Alternative Stochastic Processes," Journal of Financial Economics, 3, 145-166.

[31] Das, S., and R. Sundaram (2003): A Simple Model for Pricing Securities with Equity, Interest-Rate, and Default Risk, Working Paper, Santa Clara and New York University.

[32] Davydov, D., and V. Linetsky (2001): Pricing and hedging pathdependent options under the CEV process, Management Science, Vol. 47, No. 7, pp. 949-965.

[33] Davydov, D., and V. Linetsky (2003): Pricing Options on Scalar Diffusions: An Eigenfunction Expansion Approach, Operations Research, 51, pp. 185-209.

[34] Delbaen, F., and H. Shirakawa (2002): A note on Option Pricing for Constant Elasticity of Variance Model, Asia-Pacific Financial Markets 9 (2), 85-99.

[35] Driessen, J. (2005): Is Default Event Risk Priced in Corporate Bonds?. Review of Financial Studies, 18 , 165-195.

[36] Duffie, D., and K. Singleton (2003): Credit Risk: Pricing, Measurement, and Management, Princeton University Press. 
[37] Duffie, D., and D. Lando (2001): Term Structures of Credit spreads with Incomplete Accounting Information, Econometrica, 69, 633-664.

[38] Emanuel, D., and J. MacBeth (1982): Further Results on the Constant Elasticity of Variance Call Option Pricing Model, Journal of Financial and Quantitative Analysis, 17, Nov., 533-54.

[39] Eom, Y.H., J. Helwege, and J. Huang (2004): Structural Models of Corporate Bond Pricing: An Empirical Analysis, Review of Financial Studies, 17, 499-544.

[40] Forde, M. (2005): Semi model-independent computation of smile dynamics and greeks for barriers, under a CEV-stochastic volatility hybrid model, Department of mathematics, University of Bristol.

[41] Goldenberg, D. (1991): A Unified Method for Pricing Options on Diffusion Processes, Journal of Financial Economics, 29 Mar., 3-34.

[42] Guha, R., and A. Sbuelz (2005): Structural Recovery of Face Value at Default, http://papers.ssrn.com/sol3/papers.cfm?abstract_id=869366.

[43] Henderson, V., and D. Hobson (2003): Coupling and option price comparisons in a jump-diffusion model, Stochastics: An International Journal of Probability and Stochastic Processes, Volume 75, pp. 79-101.

[44] Hui, C.H, C.F. Lo, and S.W. Tsang (2003): Pricing corporate bonds with dynamic default barriers, Journal of Risk, Vol.5, pp.17-37.

[45] Hull, J., I. Nelken, and A. White (2004): Merton's Model, Credit Risk, and Volatility Skews, Journal of Credit Risk Vol 1, No 1, pp 1-27.

[46] Jacod, J., and A.N. Shiryaev (1988): Limit Theorems for Stochastic Processes. Springer, Berlin.

[47] Jarrow, R.A., and S. Turnbull (1995): Pricing derivatives on financial securities subject to credit risk, Journal of Finance 50, pp. 53-85. 
[48] Lando, D. (2004): Credit Risk Modeling: Theory and Applications, Princeton Series in Finance.

[49] Leland, H.E., and K.B. Toft (1996): Optimal capital structure, endogenous bankruptcy, and the term structure of credit spreads, Journal of Finance 51, pp. 987-1019.

[50] Leung, K.S., and Y.K. Kwok (2005): Distribution of occupation times for CEV diffusions and pricing of $\alpha$-quantile options, Department of Mathematics, Hong Kong University of Science and Technology, Hong Kong.

[51] Linetsky, V. (2004): Lookback Options and Diffusion Hitting Times: A Spectral Expansion Approach, Finance and Stochastics, 8, pp. 373-398.

[52] Linetsky, V. (2006): Pricing Equity Derivatives subject to Bankruptcy, Mathematical Finance, 16 (2), pp. 255-282.

[53] Lo, C.F., C.H. Hui, and P.H. Yuen (2000): Constant elasticity of variance option pricing model with time-dependent parameters, International Journal of Theoretical and Applied Finance, 3 (4), 661-674.

[54] Lo, C.F., C.H. Hui, and P.H. Yuen (2001): Pricing barrier options with square root process, International Journal of Theoretical and Applied Finance, 4 (5), 805-818.

[55] Lo, C.F., H.M. Tang, K.C. Ku, and C.H. Hui (2004): Valuation of single-barrier CEV options with time-dependent model parameters, Proceedings of the 2nd IASTED International Conference on Financial Engineering and Applications, Cambridge, MA.

[56] McConnel, J., and Schwartz E. (1986): LYON taming, Journal of Finance, $42,3,561-576$.

[57] Merton, R. (1974): On the Pricing of Corporate Debt: The Risk Structure of Interest Rates, Journal of Finance, 29, 449-470. 
[58] Merton, R., (1976): Option Pricing When Underlying Stock Returns Are Discontinuous, Journal of Financial Economics, 3, pp. 125-144.

[59] Naik, V., M. Trinh, S. Balakrishnan, and S. Sen (2003): Hedging Debt with Equity, Lehman Brothers, Quantitative Credit Research, November.

[60] Nelken, I. (2000): Handbook of Hybrid Instruments, John Wiley \& Sons Inc.

[61] Pan, J. (2000): Jump-Diffusion Models of Asset Prices: Theory and Empirical Evidence, Ph. D. thesis, Graduate School of Business, Stanford University.

[62] Protter, P. (1990): Stochastic integration and differential equations. A new approach. Applications of Mathematics, 21. Springer, Berlin.

[63] Saita, L. (2006): The Puzzling Price of Corporate Default Risk, Working Paper, Graduate School of Business, Stanford University.

[64] Sbuelz, A. (2005): Investment under higher uncertainty when business conditions worsen, Finance Letters, 3 (3), http://www.globalecofinance.com/Article.aspx?i=164.

[65] Schaefer, S., and I. Strebulaev (2005): Structural Models of Credit Risk are Useful: Evidence from Hedge Ratios on Corporate Bonds, http://papers.ssrn.com/sol3/papers.cfm?abstract_id=556928.

[66] Schaefer, S., and I. Strebulaev (2006): Risk in Capital Structure Arbitrage, Stanford Graduate School of Business, Working Paper.

[67] Schönbucher, P.J. (2003): Credit Derivatives Pricing Models: Models, Pricing, Implementation, Wiley Finance.

[68] Schroder, M. (1989): Computing the Constant Elasticity of Variance Option Pricing Formula, Journal of Finance, 44, Mar., 211-219. 
[69] Schweizer, M. (2001): A Guided Tour through Quadratic Hedging Approaches, in: E. Jouini, J. Cvitanic, M. Musiela (eds.), Option Pricing, Interest Rates and Risk Management, Cambridge University Press , pp. 538-574.

[70] Trinh, M. (2004): ORION: A Simple Debt-Equity Model with Unexpected Default, Lehman Brothers, Quantitative Credit Research, November.

[71] Tsiveriotis, K., and C. Fernandes (1998): Valuing convertible bonds with credit risk, Journal of Fixed Income, 8 (2), 95-102.

[72] Vassalou, M., and Y.Xing, (2004): Default risk and equity returns, Journal of Finance 59, 831-868.

[73] Zhou, H. (1997): A Jump-Diffusion Approach to Modeling Credit Risk and Valuing Defaultable Securities, Finance and Economics Discussion Series 1997-15 / Board of Governors of the Federal Reserve System (U.S.). 